\title{
Thymic Enlargement in Two Cases of Graves' Disease
}

\author{
Shigenori Nakamura
}

Key words: thymic enlargement, Graves' disease, ultrasonogaphy

(Intern Med 51: 673-674, 2012)

(DOI: 10.2169/internalmedicine.51.7076)

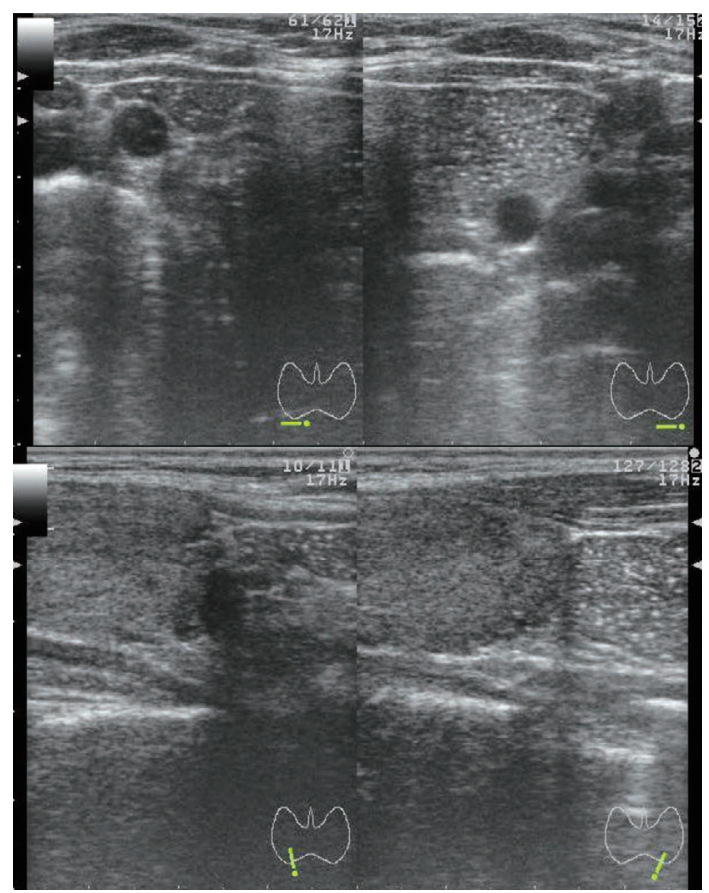

Picture 1.

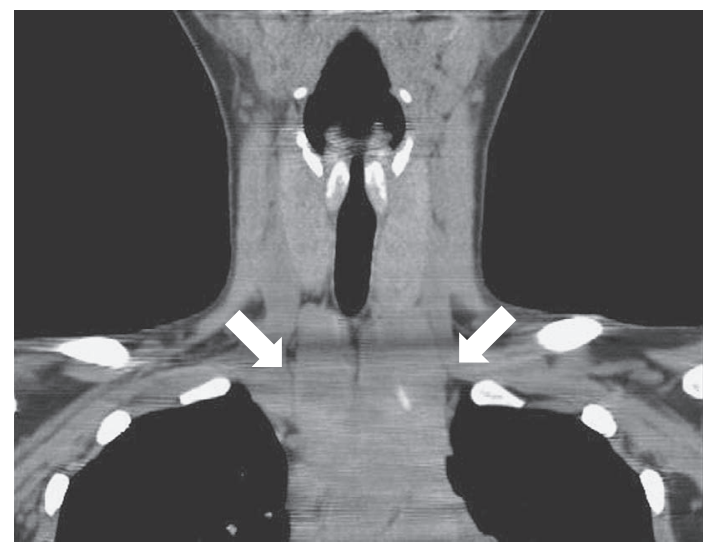

Picture 2.

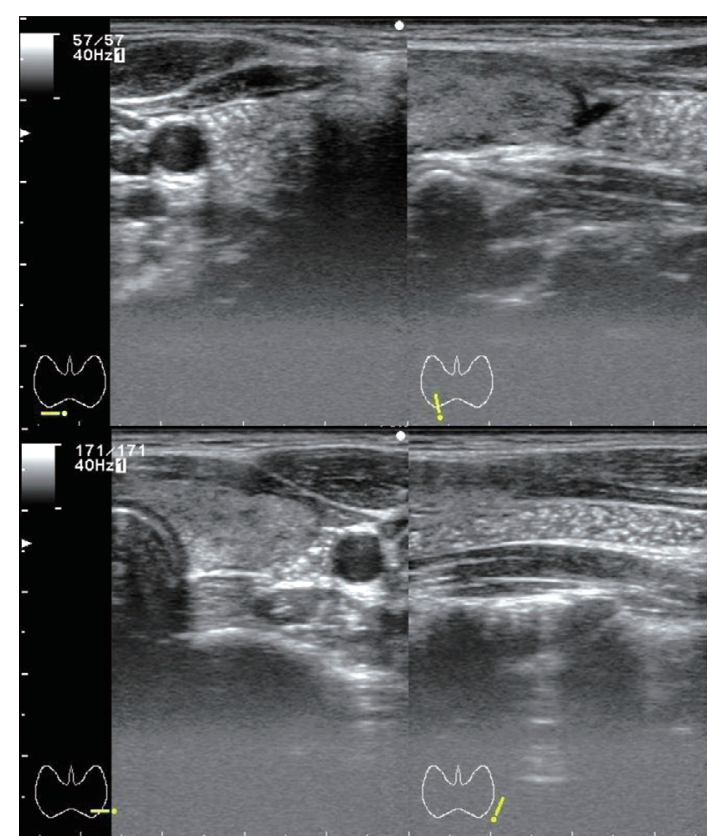

Picture 3.

A 20-year-old woman with type 1 diabetes mellitus was diagnosed as having Graves' disease. Ultrasonography of the neck revealed an enlarged thyroid (estimated weight, $31 \mathrm{~g}$ ) and a well-defined solid hypoechoic mass with inner multiple echogenic particles inferior to the thyroid gland (Picture 1). Computed tomography detected an enlarged mass just below the thyroid gland (Picture 2). The shape of the mass was similar to that of the thyroid gland. Thus, a diagnosis of thymic enlargement was made $(1,2)$. After methimazole treatment for about 1 year, the thymic enlargement resolved. We also had another patient with Graves' disease (12-year-old boy) who showed a similar mass inferior and lateral to the thyroid gland (Picture 3). The present cases indicate that ultrasonography is a useful tool for detecting thymic enlargement in some patients with Graves' disease.

Thyroid and Diabetic Division, Department of Internal Medicine, Japanese Red Cross Gifu Hospital, Japan

Received for publication December 8, 2011; Accepted for publication December 14, 2011

Correspondence to Dr. Shigenori Nakamura, nakamura55152000@yahoo.co.jp 
Intern Med 51: 673-674, 2012 DOI: 10.2169/internalmedicine.51.7076

The author states that he has no Conflict of Interest (COI).

\section{References}

1. Nakamura T, Murakami M, Horiguchi $H$, et al. A case of thymic enlargement in hyperthyroidism in a young woman. Thyroid 14: 307-310, 2004.

2. Carvalho MR, Dias T, Baptista F, do Carmo I. Graves' disease and massive thymic hyperplasia. Thyroid 20: 227-229, 2010.

\footnotetext{
(C) 2012 The Japanese Society of Internal Medicine http://www.naika.or.jp/imindex.html
} 